\title{
COMPARATIVE ANALYSIS OF INDIGENOUS AND NON-INDIGENOUS HOUSEHOLD DIETARY DIVERSITY STATUS: THE CASE OF BAMBASI, BENISHANGUL GUMUZ REGIONAL STATE, WESTERN ETHIOPIA
}

\author{
${ }^{a} A n d u a m l a k$ Assaye*, bChanyalew Seyoum, bEric Ndemo \\ a Assosa Agricultural Research Center; P. Box 256 Assosa, Ethiopia. \\ ${ }^{b}$ Haramaya University P. Box 138 Dire Dawa, Ethiopia.
}

\section{ART I C L E IN F O}

\section{Article history}

Received: April 14, 2020

Revised: July 15, 2020

Accepted: August 10, 2020

\section{Keywords}

Dietary diversity

Indigenous household

Non-indigenous household

Ordered logit model,

Bambasi Ethiopia

\section{A BS T R A C T}

Low dietary diversity in the rural household is a major problem in developing countries due to different factors. The aim of this study is to assess dietary diversity level and its associated factors among indigenous and nonindigenous households in Bambasi district, Western Ethiopia. A cross sectional data which covered a sample of 260 households collected using a semi structured interview schedule. A multi stage sampling procedure was used. A household dietary diversity score based on 12 food groups was created using seven days recalls. A descriptive statistics analysis was applied. An order logistic regression model was used to determine the factors that influence both indigenous and nonindigenous household dietary diversity. The result of the study revealed that indigenous household had better dietary diversity status than nonindigenous household heads. Age of the household heads, access to extension and access to nearest markets are the major determinants of rural households in the area. Despite of this, access to credit, farm income, farm size and dependency ratio are the major determinants for nonindigenous household heads whereas participation in small scale irrigation and education are major factors of dietary diversity of the indigenous household heads. Therefore, we recommended that food and nutrition interventions focusing on improving dietary diversity and quality should due attention to develop community specific interventions instead of generalized interventions. However, further investigation focused on seasonal dietary diversity and individual level dietary diversity of the study area.

Corresponding Author: Anduamlak Assaye

Email: anduamlak20@gmail.com

(C) The Author(s) 2020.

\section{INTRODUCTION}

Globally, more than 800 million people are suffering from food insecurity and malnutrition due to consumption of monotonous food groups. The monotonous consumption habits of the population of the world related with low level of income, climate change, conflict and war, population growth and others (WHO, 2018). This indicates the food insecurity directly or indirectly contributes to under-nutrition and over-nutrition, and high rate of multiple forms of malnutrition coexist in many countries especially low and middle-income counties and concentrated among the poor.

In developing countries, majority of households resides in rural areas and their livelihoods are obtained from agriculture and other agriculture related activities; increasing agricultural productivity is seen as the critical step for ensuring sustainable food security 
(Headey \& Ecker, 2013). The growing substantial evidence on dietary diversity indicates that the success of agricultural productivity depends on the expansion of market opportunity (Jones, 2017) and Somé and Jones (2018), utilization of improved agricultural technologies, and improvement of access to different services like extension (health and agriculture), credit services, information access and expansion of formal and informal education in Ethiopia.

The prevalence and coexistence of different forms of malnutrition could be exists not only within the countries and communities but also within the households and individual persons may affects throughout their lifetime WHO (2018). Malnutrition affects all segments of world population even if there is a disparity in the distribution, prevalence and forms of malnutrition.

The food consumption trend in Ethiopia is neatly associated with settlement of the population, cultural taboos and religious practices. For instance, the Orthodox church followers are restricted to consume animal derived food sources during the fasting seasons which accounts for five to seven months per year for adults (Belwal and Tafesse (2010). Therefore, in Ethiopia, the consumption habits of foods largely depend on cereals and low dense food varieties and limited animal source foods (Girma and Degnet (2015); Workicho et al. (2016); Misker, Misker, and Ayele (2016).

The traditional dietary practices show disparity among indigenous and non-indigenous households that involves the consumption of locally available and processed foods. It is the assumption of disparity is being driven in large parts by change in the agricultural production system and eventually in food production and consumption. This disparity is bold in low and middle-income countries since these countries may use produce food and commercial crops and livestock in a traditional way. This traditional production system of agriculture leads to limited consumption of diverse and nutritious food groups to enhance health and the health system of the people. According to Kuhnlein, Erasmus, and Spigelski (2009), indigenous households had better food consumption habits than non-indigenous households since the indigenous households consumed wild plants and animals in addition to farm products. This study aims to compare the dietary diversity status of the indigenous and non-indigenous households and to identify the major determinants of dietary diversity status of the two communities in the study area.

\section{METHODOLOGY}

Research Sample

Bambasi district was selected purposively. A cross sectional survey design was used. In this study, the total population of the district was divided into groups by using ethnics (indigenous and non-indigenous households). The participants were selected from a list of communities from the selected kebeles. For this study, a total of 260 households were randomly selected from five kebeles of the district. Among the total sampled households there were about 111 indigenous households and 149 non-indigenous households which were selected and interviewed to obtain information on the dietary diversity difference between these ethnic groups. A survey was conducted by using a semi structured interview schedule. All respondents of indigenous households were local language speakers (Bertigna) in addition to the Amharic language whereas the non-indigenous households were spoken of Amharic and Affan Oromo. Therefore, the interview schedules are initially prepared in English and translated in Amharic. This interview schedule consists of socio-demographic characteristics, economic activities, farming systems, food consumption habit, and other cross cutting issues which related to dietary diversity. This interview schedule was adopted from (FAO., 2011) guidelines and followed the standard procedures and technical issues of the survey instrument. The survey instrument was pretested and made comprehensive modifications based on feedbacks. Seven days recall of the Household Dietary Diversity Score (HDDS) questionnaire with 12 food groups was used to determine dietary habits and quality of food consumption of these households (FAO., 2011).

A written permission for the collection data was obtained from the Haramaya University department of Rural Development and Agricultural Extension, Ethiopian agricultural research institute and Bambasi district agriculture office. Both Microsoft excel (Ms Excel 2010) and Statistical Package for Social Science software version 22 (SPSS Version 22) was used to analysis the data. Descriptive and econometric model analysis were used to assess the consumption and dietary diversity difference of rural indigenous and non-indigenous households. The model fitness and the presence of multicollinearity were assessed. The data 
was presented as average, percentage and standard deviation.

\section{Empirical Model Specification}

The general objective of this study was to examine the major determinant of rural indigenous and nonindigenous household dietary diversity of the study area. Determinants of dietary diversity is a composed of many factors including socio-economic factors, biophysical, demographic factors, and other issues. Therefore, to examine the dietary diversity of the rural households needs appropriate model to accommodate all these aspects of data and to reach feasible and pertinent outcomes. Research studies on the household dietary diversity were analyzed by using different econometric models (Kiboi, Kimiywe, and Chege (2017); Taruvinga, Muchenje, and Mushunje (2013); (Pauzé, Batal, Philizaire, Blanchet, \& Sanou, 2016); Gebremedhin et al. (2017); Demeke, Meerman, Scognamillo, Romeo, and Asfaw (2017). However, this study was categorical and ordinal in nature. The outcome of this study represents an underlying continuous scale subdivided into three categories; the best modelling framework is an ordered logistic model (Greene (2002); Gujarati and Porter (1999); Long and Freese (2006); Ingelmo, Molina, de Paz, and Visconti (2011). The ordered logistic model is widely used for analyzing such categorical dependent variables Greene (2002); Gujarati and Porter (1999); Train (2009).

Dietary diversity is divided into three categories in ascending order of diversity and codes as: $0=$ low dietary diversity (LDD), 1 = medium dietary diversity (MDD) and 2 = high dietary diversity (HDD). Let "y" denote the observed dietary diversity level in the household $\mathrm{i}, \mathrm{y}^{*}$ the latent dietary diversity measure. " $\mathrm{x}$ " is the matrix of independent variables. In this study, $\mathrm{j}=$ 3 . The latent regression of dietary diversity of the $\mathrm{yi}^{*}$ is expected as:

$y_{i}^{*}=x_{i} \beta+\beta_{i}$

Where $\mathrm{i}$ is the observation, $\beta$ are the regression coefficients for " $x$ ", is the identically and independently distributed error term.

Let $\mu_{\kappa}$ be the dietary diversity thresholds $=1,2 \ldots$ j. level $\kappa=1$ represents the minimum threshold (low dietary diversity). The values of " $y$ " are represented as

$\mathrm{y}=0$ low dietary diversity (LDD) if $\mathrm{y}^{*} \leq \mu 1$

$y=1$ medium dietary diversity (MDD) if $\mu 1<y^{*} \leq \mu 2$
(2)

$y=2$ high dietary diversity (HDD) if $y^{*}>\mu 3$

Where a " $\mathrm{j}$ " denotes number of dietary diversity levels (categories). The general form of the probability that the observed y falls into category $j$ and the " $\mu$ "s and the " $\beta$ "s are to be estimated with an ordinal logit model is $\operatorname{Prob}(y=j)=1-L\left(\mu_{j-1}-\sum_{i}^{k} B_{k} x_{k}\right) \ldots \ldots \ldots$ (3)

Where $\mathrm{L}=$ represents the cumulative logistic distribution. The " $\beta$ " values for all $j$ dietary diversity levels are the same. However, this parallel line assumption may very often not hold (Sasidharana and Menéndez, 2014).

\section{RESULTS AND DISCUSSION \\ Socio-demographic characteristics}

Table 1 shows that most of the sample (80.0\%) of the head households was men. The age distribution of the respondents ranged from 23-71 years. Of the total sample, 80.18 and $83.22 \%$ of indigenous and nounindigenous household heads were married, respectively.

The mean age of indigenous household heads and nonindigenous household heads were $45 \pm 10.44$ and $47.54 \pm 9.52$ years, respectively. The descriptive and inferential analysis result of the two ethnic groups shows mean significance difference between age of household heads from indigenous and non-indigenous household at less than one percent. The comparison in family sizes was recorded higher from indigenous households $(4.95 \pm 1.99)$ than non-indigenous households $(4.11 \pm 1.36)$ in the study area. The t-test result revealed that there is a significant mean difference of family size between indigenous and nonindigenous households at $<1 \%$ (Table 1 ).

There is a significant mean difference between indigenous and non-indigenous households of the household head annual farm income $(9600 \pm 529$ and $9360 \pm 854$ in ETB, respectively). Similarly, mean annual off/non-farm income of the household heads show, there is a significant mean difference between two ethnic groups in the study area. About $30.63 \%$ of indigenous household heads were illiterate while $26.17 \%$ of non-indigenous were illiterate. Similarly, the non-indigenous household heads have higher number of attending formal education than indigenous household heads (Table 1). 
Table 1. Socio-demographic characteristics of the study population of Bambasi district.

\begin{tabular}{|c|c|c|c|c|c|}
\hline \multirow{2}{*}{ Variable } & \multicolumn{2}{|c|}{ Indigenous $(\mathrm{N}=111)$} & \multicolumn{2}{|c|}{ Non-indigenous $(\mathrm{N}=149)$} & \multirow{2}{*}{ t values } \\
\hline & Mean or $\%$ & SD & Mean or $\%$ & SD & \\
\hline Family size (AE) & 4.95 & 1.994 & 4.11 & 1.364 & $4.041^{* * *}$ \\
\hline Dependency ratio & 1.08 & 0.765 & 0.87 & 0.672 & $2.393^{* *}$ \\
\hline Age of household head & 45.00 & 10.435 & 47.54 & 9.521 & $-2.045^{* *}$ \\
\hline Farm size (ha) & 2.12 & 0.896 & 1.37 & 0.785 & $7.218^{* * *}$ \\
\hline Livestock Ownership (TLU) & 5.76 & 3.962 & 4.74 & 3.530 & $2.191^{* *}$ \\
\hline Crop diversity (CDI) & 0.28 & 0.057 & 0.27 & 0.072 & 0.559 \\
\hline Annual farm income (ETB) (x 1000) & 9.60 & 0.529 & 9.30 & 0.854 & $3.195^{* * *}$ \\
\hline Off/non-farm income (ETB) (x 1000) & 1.47 & 3.270 & 2.95 & 4.137 & $3.109 * * *$ \\
\hline Market distance $(\mathrm{km})$ & 7.18 & 1.215 & 10.75 & 2.010 & $-16.594^{* * *}$ \\
\hline Sex (being male) & 78.38 & & 81.21 & & 0.318 \\
\hline \multicolumn{6}{|l|}{ Marital status } \\
\hline Married & 80.18 & & 83.22 & & \\
\hline Divorced/separated & 9.01 & & 7.38 & & $9.026^{*}$ \\
\hline Widowed & 10.81 & & 9.40 & & \\
\hline \multicolumn{6}{|l|}{ Educational Status } \\
\hline Illiterate & 30.63 & & 26.17 & & \\
\hline Able read and write & 27.93 & & 28.19 & & 0.836 \\
\hline Primary school & 36.94 & & 41.61 & & \\
\hline Secondary school & 4.50 & & 4.03 & & \\
\hline Home gardening (yes \%) & 94.59 & & 87.25 & & $3.950^{* *}$ \\
\hline Participation in irrigation (yes \%) & 90.09 & & 43.62 & & $59.230^{* * *}$ \\
\hline Access to Extension (yes \%) & 90.99 & & 79.19 & & $6.664^{* *}$ \\
\hline Access to credit (yes \%) & 84.68 & & 62.42 & & $15.621^{* * *}$ \\
\hline
\end{tabular}

${ }^{* * *},{ }^{* *}, \&{ }^{*}$ statistically significant at 1,5 and $10 \%$, respectively

The comparison in the participation of in an irrigation scheme revealed that the indigenous household head were higher than to their counterpart in the area. As indicated in Table 1 about $90.09 \%$ of indigenous households and $43.62 \%$ of non-indigenous households were participated in small scale irrigation scheme to produce seasonal and perennial crops. This shows there is statistically significant proportional difference between those societies at $p<0.001\left(x^{2}=59.23\right)$.

\section{Food consumption of indigenous and non- indigenous households}

In Ethiopia the consumption pattern of the population is diverse, and, unlike other developing countries, no single crops dominate the national food baskets (Berhane et al., 2012). This indicates that the food basket of Ethiopian households consists of a wide variety of staple and grains. In this regard, the quality, quantity and composition of food consumption vary by place of residence, agroecology, ethnic cultural trends, socioeconomic level of the people and livelihood strategy.

The regional consumption patterns generally relay on staple starch food and food grains. For instance, Benishangul Gumuz consistent with production potential of cereal crops such as maize, sorghum, finger millet, the population were the highest consumers of cereal crops as well as legume crops (ground nut, chick pea) (Berhane et al., 2012). Therefore, the consumption behaviour of the sampled households as observed were relied on cereals and legumes or protein rich sources of food. 
Table 2. Food group consumption between indigenous and non-indigenous households.

\begin{tabular}{lccc}
\hline \multirow{2}{*}{ Food group } & Indigenous $(\mathrm{n}=111)$ & Non-indigenous $(\mathrm{n}=149)$ & $\begin{array}{c}\text { Chi-square } \\
\text { test (X2) }\end{array}$ \\
\cline { 2 - 3 } Cereals & Percent & Percent & - \\
White root \& tuber & 100.00 & 100.00 & $6.122^{* *}$ \\
Vegetable & 41.44 & 26.80 & $5.087^{* *}$ \\
Fruits & 62.16 & 75.17 & 0.233 \\
Meat & 17.12 & 19.46 & 0.405 \\
Egg & 42.34 & 46.31 & $19.087^{* * *}$ \\
Fish & 49.55 & 23.49 & $5.917^{* *}$ \\
Legume & 7.21 & 1.34 & 1.092 \\
Milk \& dairy products & 37.84 & 44.30 & $16.44^{* * *}$ \\
Oil & 84.68 & 61.74 & 0.131 \\
Sweet & 91.89 & 90.60 & 0.634 \\
Spice & 77.48 & 73.15 & $13.014^{* * *}$ \\
\hline
\end{tabular}

***, and ${ }^{* *}$ statistically significant at $1 \%$ and $5 \%$, respectively

The observed distribution of food varieties consumption suggests that on average, both societies' diets are commonly dominated by food groups of cereals, oils, condiments and sugars (sweet). This may show the communities of the study area the consumption of food variety are more crops and crops products rather than animal derived food groups (exceptional milk and dairy products). Table 2 shows the proportional consumption of various food groups by the indigenous and non-indigenous households of the study area. There is statistically difference between indigenous households and nonindigenous households in consumption of some food groups: white and root and tubers, vegetables, spices, eggs, milk and dairy products and fish. Therefore, the study shows the indigenous households consumed better in terms of food variety than the nonindigenous households. Similarly, as compared within the animal derived food, based on the proportion consumption, of all other animal derived foods; milk had the highest consumption and fish had the least food groups by both indigenous and non-indigenous households in the study area. From animal derived food groups, the indigenous households were better consumers than the non-indigenous households. Evidently, the consumption of white root and tuber, eggs, fish, milk and dairy products, oils, and sugar and sweets food groups by indigenous households was much higher than for the nonindigenous households. In general, the culinary and consumption habits in each groups of the society are homogeneous in relation to the consumption of cereals, oil and spice food groups.

Dietary diversity of indigenous and nonindigenous households

The dietary diversity categories of the study population were conducted by adapting the FAO (2011) version of dietary diversity guideline. According to the FAO guideline we create mutually exclusive categories of dietary diversity as derived from 12 food groups into; low, medium and high dietary diversity. Based on this category, Figure 1 shows that the three categories of indigenous and non-indigenous household heads dietary diversity status. Generally, the study revealed that the indigenous household heads have the smallest number of low dietary diversity status than the nonindigenous household heads. Comparing dietary diversity status of the two ethnic groups, indigenous household heads have better than the counter part in the study area (fig. 1). This distinct proportional difference in household dietary diversity status was statistically significant at $(\chi 2=9.514) \mathrm{p}<0.001$. The mean dietary diversity score for indigenous household heads were $2.14 \pm 0.06$ and for nonindigenous household heads were $2.03 \pm 0.07$ ). This shows that indigenous households were relatively higher dietary diversity score than non-indigenous household heads. About $84.70 \%$ of the indigenous households and $70.5 \%$ of non-indigenous households were consumed more than four food groups within seven days recalling period. 


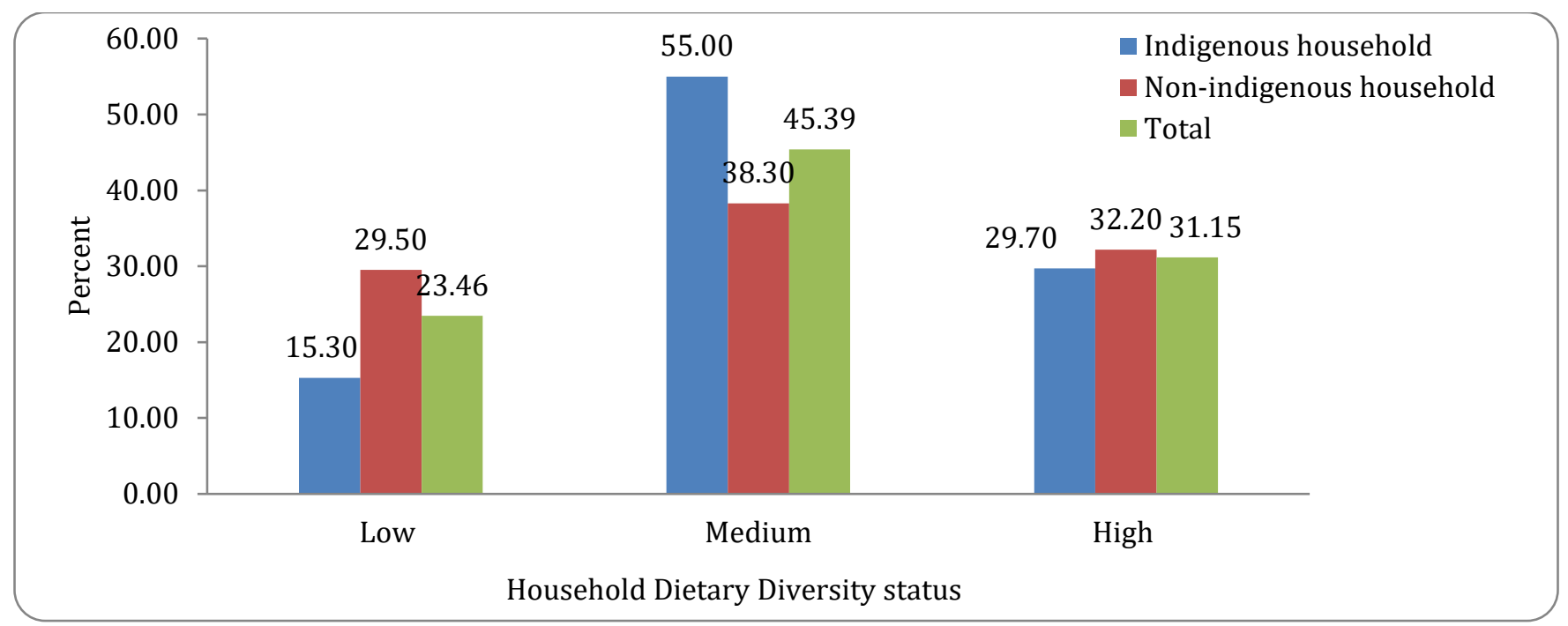

Figure 1. Comparison of dietary diversity condition of indigenous and nonindigenous households.

\section{Determinants of Household Dietary Diversity}

The ordered logistic regression analysis shows that age of the household heads was an important determinant of dietary diversity status of the study area. This was true for both study societies, but the marginal effects analysis of the household dietary diversity has different values. A one-year increases in the age of the indigenous and nonindigenous household head increases by the probability of falling into higher dietary diversity by nearly $1 \%$ reduces the likelihoods of being low dietary diversity by $0.32 \%$ and $0.87 \%$ of indigenous and nonindigenous households of the study population, respectively. Those who are old aged household heads may have more experiences in social and physical environment and have accumulated knowledge of farm production as well as food nutritional values than young aged household. These findings are supported by those of Demeke et al. (2017) in Kenya and Gebrehiwot (2008) in Ethiopia.

The other significant factor for study households was dependency ratio. The households with lowest dependent members in the households found to be in higher household dietary diversity. This was true for nonindigenous society but not for indigenous society. The result show that dependency ratio has strongly and negatively significant relationship with better dietary diversity $(\mathrm{P}<0.001)$. The household could diversify their job opportunities by coordinating and contributing their labor for agricultural production and income generation. It expected that when the household members are involved in different job opportunities for diversifying their income, they can improve the purchasing power of various food items and enable the household to become high dietary diversity status. This result supported by study done in Ethiopia (Workicho et al. (2016) and India (Parappurathu, Kumar, Bantilan, and Joshi (2015).

The household educational level has a relationship with dietary diversity. In the present study, indigenous household heads were more significantly influenced by education status. This could be that education has a significant relationship with household dietary diversity. However, the magnitude and the direction of the predictor variables were not similar. As indicated in Table 3 the household which did not attend formal education (illiterate) had a negative and significant influence on high dietary diversity while the household who is able to read and write has a negative and significant relationship with household dietary diversity for indigenous households; however, this was not true for nonindigenous households. More educated household could ensure the household members to be diversified food consumers through gaining information from various sources. Education improves the knowledge health and nutrition but also lowers the cognitive cost associated with consuming a variety of food items. The educated household head assign a significant proportion of food budget to various food groups (Block (2004); Parappurathu et al. (2015) that are nutritionally dense mainly since they have a greater awareness and understanding of health benefits of food groups (Smith (2004). 
Table 3. Maximum likelihood estimates of ordered logistic regression analysis for indigenous households (N=111).

\begin{tabular}{|c|c|c|c|c|c|c|c|}
\hline \multirow{3}{*}{ DD1SLEVEL } & \multirow{3}{*}{ Coef. } & \multirow{3}{*}{ Std. Err. } & \multirow{3}{*}{$\mathrm{Z}$} & \multirow{3}{*}{$\mathrm{P}>|\mathrm{z}|$} & \multicolumn{3}{|c|}{ Marginal effects of HDDS level } \\
\hline & & & & & LDD & MDD & HDD \\
\hline & & & & & $\mathrm{dy} / \mathrm{dx}$ & $\mathrm{dy} / \mathrm{dx}$ & $\mathrm{dy} / \mathrm{dx}$ \\
\hline AGE & 0.075 & 0.030 & 2.52 & $0.012^{* *}$ & -0.0032 & -0.0059 & 0.0092 \\
\hline SEXHEAD (Female) & 2.281 & 1.708 & 1.33 & 0.182 & -0.0983 & -0.1805 & 0.2789 \\
\hline MARTALST (Married) & 1.981 & 1.123 & 1.76 & $0.078^{*}$ & -0.0854 & -0.1568 & 0.2422 \\
\hline ADULT_EQUVT & -0.175 & 0.178 & -0.98 & 0.326 & 0.0075 & 0.0138 & -0.0214 \\
\hline DEPRATIO & -0.314 & 0.417 & -0.75 & 0.452 & -0.0135 & -0.0249 & 0.0384 \\
\hline ILLITRATE & 3.873 & 1.503 & 2.58 & $0.010^{* *}$ & 0.1671 & 0.3066 & -0.4737 \\
\hline ABLREADWRT & 3.126 & 1.462 & 2.14 & $0.032^{* *}$ & -0.1348 & -0.2475 & 0.3822 \\
\hline PRIMARY & 2.524 & 1.402 & 1.8 & $0.072^{*}$ & -0.1089 & -0.1998 & 0.3087 \\
\hline FARMSIZE & 0.165 & 0.389 & 0.42 & 0.673 & -0.0071 & -0.0130 & 0.0201 \\
\hline CDI & -9.458 & 5.415 & -1.75 & $0.081^{*}$ & -0.4079 & -0.7487 & 1.1566 \\
\hline LIVEUNIT & -0.046 & 0.070 & -0.66 & 0.509 & 0.0020 & 0.0037 & -0.0056 \\
\hline HOMEGARD & -0.092 & 1.127 & -0.08 & 0.935 & 0.0040 & 0.0073 & -0.0112 \\
\hline FARMICOME & -0.509 & 0.678 & -0.75 & 0.452 & 0.0220 & 0.0403 & -0.0623 \\
\hline OFF-INCOME & -0.084 & 0.079 & -1.06 & 0.228 & 0.0036 & 0.0067 & -0.0103 \\
\hline ACCEXTN & 4.152 & 1.198 & 3.47 & $0.001^{* * *}$ & -0.1791 & -0.3287 & 0.5077 \\
\hline CREDIT & -0.421 & 0.719 & -0.59 & 0.558 & 0.0182 & 0.0333 & -0.0515 \\
\hline MARKDIS & 1.050 & 0.285 & 3.69 & $0.000^{* * *}$ & 0.0453 & 0.0831 & -0.1284 \\
\hline PARTCIRR & 3.722 & 1.057 & 3.52 & $0.000^{* * *}$ & -0.1605 & -0.2946 & 0.4552 \\
\hline /cut1 & 4.535 & 9.353 & & & & & \\
\hline /cut2 & 9.380 & 9.398 & & & & & \\
\hline
\end{tabular}

***, and ${ }^{* *}$ statistically significant at $1 \%$ and $5 \%$, respectively

Note: HDDS= Household Dietary Diversity Score;

According to the study, farm size was another determinant of dietary diversity in the area. However, this was not true for indigenous society. Farm size of the nonindigenous household heads influenced positively and significantly household dietary diversity at less than $1 \%$ probability level. A one-unit increase in the land holding of the household head increases by the likelihood of falling into higher dietary diversity by nearly $21 \%$ and reduces the probability of falling into a lower dietary diversity by $19.39 \%$. This could be explained by the probability that greater farm size increases farmers cultivate more diverse crop types which in turn would help them to produce more yields. The successful more production helps to enhance and improve the consumption of diversified food groups of the households. This study is consistent with the study undertaken by Mbwana (Mbwana, Kinabo, Lambert, and Biesalski (2016). 
Table 4. Maximum likelihood estimates of ordered logistic regression analysis for nonindigenous households $(\mathrm{N}=$ 149).

\begin{tabular}{|c|c|c|c|c|c|c|c|}
\hline \multirow{3}{*}{ DD1SLEVEL } & \multirow{3}{*}{ Coef. } & \multirow{3}{*}{ Std. Err. } & \multirow{3}{*}{$\mathrm{z}$} & \multirow{3}{*}{$P>|z|$} & \multicolumn{3}{|c|}{ Marginal effects of HDDS level } \\
\hline & & & & & LDD & MDD & HDD \\
\hline & & & & & $\mathrm{dy} / \mathrm{dx}$ & $\mathrm{dy} / \mathrm{dx}$ & $\mathrm{dy} / \mathrm{dx}$ \\
\hline AGE & 0.050 & 0.021 & 2.37 & $0.018^{* *}$ & -0.0087 & -0.0007 & 0.0094 \\
\hline SEXHEAD (Female) & 0.416 & 0.886 & 0.47 & 0.639 & -0.0728 & -0.0056 & 0.0784 \\
\hline MARTALST(Married) & 0.042 & 0.548 & 0.08 & 0.939 & -0.0073 & -0.0006 & 0.0079 \\
\hline ADULT_EQUVT & 0.230 & 0.150 & 1.53 & 0.126 & -0.0402 & -0.0031 & 0.0433 \\
\hline DEPRATIO & 0.881 & 0.301 & 2.93 & $0.003^{* * *}$ & 0.1540 & 0.0118 & -0.1658 \\
\hline ILLITRATE & 2.745 & 1.867 & 1.47 & 0.142 & 0.4799 & 0.0369 & -0.5168 \\
\hline ABLREADWRT & -2.070 & 1.808 & -1.14 & 0.252 & 0.3618 & 0.0278 & -0.3896 \\
\hline PRIMARY & 1.582 & 1.810 & 0.87 & 0.382 & -0.2765 & -0.0213 & 0.2978 \\
\hline SECONDARY & 0.660 & 2.095 & 0.32 & 0.753 & -0.1154 & -0.0089 & 0.1243 \\
\hline FARMSIZE & 1.109 & 0.336 & 3.30 & $0.001^{* * *}$ & -0.1939 & -0.0149 & 0.2088 \\
\hline CDI & 0.042 & 2.627 & 0.02 & 0.987 & -0.0074 & -0.0006 & 0.0080 \\
\hline LIVEUNIT & -0.001 & 0.061 & -0.01 & 0.995 & 0.0001 & 0.0001 & -0.0002 \\
\hline HOMEGARD & -0.186 & 0.557 & -0.33 & 0.739 & 0.0325 & 0.0025 & -0.0350 \\
\hline FARMICOME & 1.494 & 0.352 & 4.25 & $0.000^{* * *}$ & -0.2612 & -0.0201 & 0.2813 \\
\hline OFF-INCOME & -0.001 & 0.044 & -0.03 & 0.976 & 0.0002 & 0.0000 & -0.0002 \\
\hline ACCEXTN & 1.399 & 0.437 & 3.21 & $0.001^{* * *}$ & -0.2446 & -0.0188 & 0.2634 \\
\hline CREDIT & 0.781 & 0.383 & 2.04 & $0.042^{* *}$ & -0.1365 & -0.0105 & 0.1470 \\
\hline MARKDIS & 0.259 & 0.101 & -2.56 & $0.010^{* *}$ & 0.0454 & 0.0035 & -0.0489 \\
\hline PARTCIRR & -0.004 & 0.367 & -0.01 & 0.991 & 0.0007 & 0.0001 & -0.0008 \\
\hline /cut1 & 22.286 & 13.472 & & & & & \\
\hline /cut2 & 24.609 & 13.501 & & & & & \\
\hline
\end{tabular}

The other significant and important determinant of household dietary diversity was household annual farm income. It was found that households with a low annual farm income were more likely to be lower dietary diversity compared to those with a higher farm income. But this was not true for all study societies. Annual farm income had positively and significantly influence on the nonindigenous household but not for indigenous household in relation to dietary diversity conditions. A one-unit (ETB) increase in the annual farm income of the nonindigenous household head increases the likelihood of falling into higher dietary diversity by $28.13 \%$ and reduces the probability of falling into lower dietary diversity by $26.12 \%$. This might be since the nonindigenous rural households obtain their wealth (income) from selling agricultural products and purchase food crops to fill nutritional requirements. However, the indigenous households might be attaining nutritious foods through gathering and hunting wild animals and plants in addition to purchasing and on farm production. This study finding is consistent with study results reports from India (Parappurathu et al. (2015), China (Liu, Shively, and Binkley (2014), and Malawi (Jones, Shrinivas, and Bezner-Kerr (2014).

According to the study, access to agricultural extension services was another determinant of household dietary diversity. Access to agricultural extension services was positively and significantly correlated with high dietary diversity of the study populations at less than $1 \%$ probability level. But the magnitude of significant 
influence of access to extension on household dietary diversity varied across the two societies. For instance, as indicated in Table 3 and 4 the household who have the access to extension services the probability of the indigenous and non-indigenous household falls into high dietary diversity increases by $50.77 \%$ and $26.34 \%$ and reduces the likelihood of being characterized by low dietary diversity by $17.91 \%$ and $24.46 \%$, respectively. The probable reason could be extension service widens the farmers' knowledge, skill, and experiences with regards to the utilization of improved agricultural technologies and farm management practices. This successful utilization of farm operation helps to promote farm production and productivity as well as improves the consumption of diversified food groups - solve nutritional problems of chronic energy deficiency and micronutrient deficiencies of rural households.

Another factor that was correlated with household dietary diversity of both societies is the walking distance (in kilo meters) to a distant market which would negatively influence the higher dietary diversity situations. The findings of this study reveal that households that are walking more distance for getting market place is more likely to have lower dietary diversity than the households who have less walking distance. This confirms that reducing the walking distance to the local market by one kilo meter would have a larger positive effect on household dietary diversity. This implies that the nearest market access matters for dietary quality of farm households. However, the magnitude of significance influences the market distance on household dietary diversity was different across the societies. For example, all other things constant, a one-unit $(\mathrm{km})$ increase in the market distance for the indigenous and nonindigenous household head decreases $12.84 \%$ and $4.89 \%$ by the likelihood of falling into higher dietary diversity nearly $13 \%$ and $5 \%$ and increases the probability of falling into lower dietary diversity by $4.53 \%$ and $4.54 \%$, respectively. A shorter and better market access has a positive influence on household dietary diversity since the household head is able to be purchased better quality and various food items (Pauzé, Batal, Philizaire, Blanchet, and Sanou (2016); Babatunde, Owotoki, Heidhues, and Buchenrieder (2007).

According to the study, participation in small scale irrigation schemes was another determinant of dietary diversity in the area. Participation in small scale irrigation scheme by the household head influenced positively and significantly household dietary diversity at less than $1 \%$ probability level. However, this was not true for the nonindigenous society. This implies that the indigenous household who were participating in small scale based agricultural production more likely to have better dietary diversity at household level. This could be explained by the probability that participation in an irrigation farming of households leads to cultivation of more diverse crop types which in turn would help them to produce more yields since they can produce two or more within one cropping season. Eventually, the production of varied crops through irrigation that improves the consumption of diverse food groups from on production as well as earns more income from selling their farm products. This finding is consistence with Taruvinga et al. (2013) who reported that access to irrigation significantly and positively affects the household dietary diversity.

Access to credit is one of the most important determinants of household dietary diversity in study area. The coefficient of access to credit service by the household were positive and significant in households indicating that the households who have access to credit services were likely to be have better dietary diversity status. This is not true for nonindigenous societies. A possible explanation of the credit services receipts is economically equipped with the knowhow and awareness of how to utilize the financial resources effectively and efficiently. The positive influence of access to credit on household dietary diversity has been well acknowledged in the theoretical and empirical literature. For instance, Goshu, Kassa, and Ketema (2013) has reported a positive and significant effect on household dietary diversity of access to credit. Therefore, our findings are consistent with the theory and past empirical study findings.

\section{CONCLUSION AND RECOMMENDATION}

The purpose of this study was to examine the factors that affects the dietary diversity status among indigenous and nonindigenous rural households in Bambasi district. The study found differences in dietary diversity status between indigenous and nonindigenous households. The dietary diversity status in the study revealed that about nearly 3/4th and $2 / 3 \mathrm{rd}$ of indigenous and nonindigenous households 
consumed more than four food groups. Comparatively indigenous household have better dietary diversity status than nonindigenous one. The major factors which affect dietary diversity status of both societies are age of household head, access to extension service and distance to market. Despite this, access to credit, farm income, farm size and dependency ratio are the major determinants for nonindigenous household heads whereas participation in small scale irrigation and education are the major factors of dietary diversity of the indigenous household heads. Therefore, we recommended that food and nutrition interventions focusing on improving dietary diversity and quality should pay due attention to develop community specific interventions instead of generalized interventions. Food and nutritional security interventions focusing on promoting market access and enhancing and create better access to extension service of the societies. Additionally, government and nongovernment interventions in all significant factors that enhance and improve may be recommended to help the household to improve the diet quality and diversity in the study area. However, further investigation focused on seasonal dietary diversity and individual level dietary diversity of the study area.

\section{REFERENCES}

Babatunde, R. O., Owotoki, G. M., Heidhues, F., and Buchenrieder, G. 2007. Vulnerability and food insecurity differentials among male and femaleheaded farming households in Nigeria. Pakistan Journal of Social Sciences, 4(3): 414-418.

Belwal, R., and Tafesse, Y. 2010. A study of the impact of orthodox Christians fasting on demand for biscuits in Ethiopia. African Journal of Marketing Management, 2(3): 010-017.

Block, S. A. 2004. Maternal nutrition knowledge and the demand for micronutrient-rich foods: Evidence from Indonesia. Journal of Development Studies, 40(6): 82-105.

Demeke, M., Meerman, J., Scognamillo, A., Romeo, A., and Asfaw, S. 2017. Linking farm diversification to household diet diversification: Evidence from a sample of Kenyan ultra-poor farmers. Food security, 8: 1069-1085.

Gebremedhin, S., Baye, K., Bekele, T., Tharaney, M., Asrat, Y., Abebe, Y., and Reta, N. 2017. Predictors of dietary diversity in children ages 6 to 23 mo in largely food-insecure area of South Wollo, Ethiopia. Nutrition, 33: 163-168.

Girma, N. M. E., and Degnet, T. 2015. Dietary diversity and associated factors among rural households in South Gondar Zone, Northwest Ethiopia. Retrieved from Ethiopia:

Goshu, D., Kassa, B., and Ketema, M. 2013. Measuring diet quantity and quality dimensions of food security in rural Ethiopia. Journal of Development and Agricultural Economics, 5(5): 174-185.

Greene, W. 2002. Econometric analysis. In (pp. 1026). USA: Prentice Hall.

Gujarati, D. N., and Porter, D. C. 1999. Essentials of econometrics (Vol. 2): Irwin/McGraw-Hill Singapore.

Headey, D., and Ecker, 0. 2013. Rethinking the measurement of food security: from first principles to best practice. Food security, 5(3): 327-343

Ingelmo, F., Molina, M. J., de Paz, J. M., and Visconti, F. 2011. Soil saturated hydraulic conductivity assessment from expert evaluation of field characteristics using an ordered logistic regression model. Soil and Tillage Research, 115, 27-38.

Jones, A. D. 2017. On-farm crop species richness is associated with household diet diversity and quality in subsistence-and market-oriented farming households in Malawi. The Journal of nutrition, 147(1): 86-96.

Jones, A. D., Shrinivas, A., and Bezner-Kerr, R. 2014. Farm production diversity is associated with greater household dietary diversity in Malawi: findings from nationally representative data. Food Policy, 46: 1-12.

Kiboi, W., Kimiywe, J., and Chege, P. 2017. Determinants of dietary diversity among pregnant women in Laikipia County, Kenya: a cross-sectional study. BMC Nutrition, 3(1): 12.

Kuhnlein, H. V., Erasmus, B., and Spigelski, D. 2009. Indigenous peoples' food systems: the many dimensions of culture, diversity and environment for nutrition and health: Food and Agriculture Organization of the United Nations Rome.

Liu, J., Shively, G. E., and Binkley, J. K. 2014. Access to variety contributes to dietary diversity in China. Food Policy, 49: 323-331. 
Mbwana, H. A., Kinabo, J., Lambert, C., and Biesalski, H. K. 2016. Determinants of household dietary practices in rural Tanzania: Implications for nutrition interventions. Cogent Food \& Agriculture, 2(1): 1224046.

Misker, D., Misker, B., and Ayele, G. 2016. House hold dietary diversity and associated factors in Mirab Abaya wereda Southern Ethiopia; community based cross sectional study. Divers Equal Health Care, 13(4): 293-296.

Parappurathu, S., Kumar, A., Bantilan, M., and Joshi, P. 2015. Food consumption patterns and dietary diversity in eastern India: evidence from village level studies (VLS). Food security, 7(5): 10311042.

Pauzé, E., Batal, M., Philizaire, Y., Blanchet, R., and Sanou, D. 2016. Determinants of diet quality among rural households in an intervention zone of Grande Anse, Haiti. Food security, 8(6): 11231134.

Smith, L. 2004. Understanding the causes of food insecurity in Sub-Saharan Africa: Do the determinants of diet quantity and quality differ.

Somé, J. W., and Jones, A. D. 2018. The influence of crop production and socioeconomic factors on seasonal household dietary diversity in Burkina Faso. PLoS ONE, 13(5): e0195685.

Taruvinga, A., Muchenje, V., and Mushunje, A. 2013. Determinants of rural household dietary diversity: The case of Amatole and Nyandeni districts, South Africa. International Journal of Development Sustainability, 2(4): 2233-2247.

Train, K. E. 2009. Discrete choice methods with simulation: Cambridge university press.

WHO. 2018. The state of food security and nutrition in the world In Building climate resilience for food security and nutrition: Food and Agriculture Organization.

Workicho, A., Belachew, T., Feyissa, G. T., Wondafrash, B., Lachat, C., Verstraeten, R., and Kolsteren, P. 2016. Household dietary diversity and Animal Source Food consumption in Ethiopia: evidence from the 2011 Welfare Monitoring Survey. BMC public health, 16(1): 1192.

Publisher's note: EScience Press remains neutral with regard to jurisdictional claims in published maps and institutional affiliations.

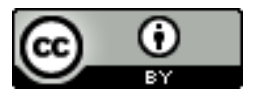

Open Access This article is licensed under a Creative Commons Attribution 4.0 International License, which permits use, sharing, adaptation, distribution and reproduction in any medium or format, as long as you give appropriate credit to the original author(s) and the source, provide a link to the Creative Commons license and indicate if changes were made. The images or other third-party material in this article are included in the article's Creative Commons license, unless indicated otherwise in a credit line to the material. If material is not included in the article's Creative Commons license and your intended use is not permitted by statutory regulation or exceeds the permitted use, you will need to obtain permission directly from the copyright holder. To view a copy of this license, visit http://creativecommons.org/licenses/by/4.0/.

(C) The Author(s) 2020. 